07

\title{
Формирование SiC-мезаструктур с пологими боковыми стенками сухим селективным травлением через маску из фоторезиста
}

\author{
(C) Н.М. Лебедева, Т.П. Самсонова, Н.Д. Ильинская, С.И. Трошков, П.А. Иванов \\ Физико-технический институт им. А.Ф. Иофрфе РАН, \\ 194021 Санкт-Петербург, Россия \\ e-mail: Natali_lebedeva@mail.ioffe.ru
}

Поступило в Редакцию 15 января 2020 г.

В окончательной редакции 15 января 2020 г.

Принято к публикации 28 января 2020 г.

Продемонстрировано формирование $\mathrm{SiC}$-мезаструктур с пологими боковыми стенками с помощью селективного реактивно-ионного травления (Reactive Ion Etching, RIE) карбида кремния через маску из фоторезиста (наклонные стенки сформированы при одновременном травлении $\mathrm{SiC}$ и резистивной маски, край которой имеет форму острого клина). Простая геометрическая модель травления предсказывает, что результирующий угол наклона стенки мезаструктуры должен задаваться двумя параметрами - исходным углом резистивного клина и селективностью травления $\mathrm{SiC}$ по отношению к фоторезисту (отношением скоростей травления $\mathrm{SiC}$ и фоторезиста). Для экспериментов использовались полированные пластины $4 H-\mathrm{SiC}$ с ориентацией (0001). На Si-стороне пластин фотолитографическими методами были нанесены площадки из фоторезиста с краевым углом $22^{\circ}$. Затем проводилось травление мезаструктур в трифториде азота в установке с индуктивно-связанной плазмой. Были подобраны параметры RIE-процесса, обеспечивающие травление $\mathrm{SiC}$ и фоторезиста со скоростями 55 и $160 \mathrm{~nm} / \mathrm{min}$ соответственно (селективность травления $1: 3$ ).

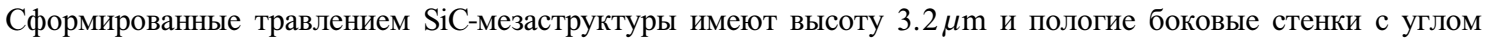
наклона около $8^{\circ}$. Данная технология может использоваться при изготовлении высоковольтных $\mathrm{SiC}$-приборов с прямой фаской.

Ключевые слова: карбид кремния, мезаструктура, наклонные стенки, фотолитография, реактивно-ионное травление.

DOI: $10.21883 /$ JTF.2020.06.49289.12-20

\section{Введение}

Карбид кремния (SiC) обладает рядом уникальных физико-химических свойств, из которых особенно выделяются высокая твердость (по твердости $\mathrm{SiC}$ уступает только алмазу и карбиду бора) и почти абсолютная химическая инертность: при нормальных условиях $\mathrm{SiC}$ не взаимодействует ни с одним из известных для других полупроводниковых материалов химических травителей. В отличие, например, от кремния в технологии $\mathrm{SiC}$-приборов механическая обработка и химическое травление не применяются. В свое время для изготовления мезаэпитаксиальных $\mathrm{SiC}$-приборов был разработан метод сухого селективного травления $\mathrm{SiC}$ в плазме фторсодержащих молекулярных газов, таких как $\mathrm{CF}_{4}, \mathrm{SF}_{6}$, и $\mathrm{NF}_{3}[1,2]$. Считается, что плазменное травление $\mathrm{SiC}$ происходит по реактивно-ионному механизму: атомы кремния удаляются с поверхности $\mathrm{SiC}$ за счет их химической реакции с ионами фтора и образования летучих молекул $\mathrm{SiF}_{4}$, а углеродные атомы - за счет их преимущественного физического распыления [3]. Благодаря низкой температуре, чистоте обработки, высокой селективности травления по отношению к некоторым металлам алюминию (порядка $10: 1)$ и никелю (порядка $100: 1)$ в настоящее время метод реактивно-ионного травления (Reactive Ion Etching, RIE) широко используется в технологии полупроводниковых приборов на основе $4 H-\mathrm{SiC}$.
Характерная особенность селективного травления $\mathrm{SiC}$ методом RIE через металлическую маску состоит в том, что стенка протравливаемой ступеньки получается строго вертикальной. Дело в том, что при травлении боковая поверхность $\mathrm{SiC}$ покрывается монослоем графита и, поскольку последняя не подвергается ионной бомбардировке, латеральное травление блокируется. Именно этим объясняется высокая анизотропия, достигаемая при травлении $\mathrm{SiC}$ методом RIE. Однако для формирования структуры мезаэпитаксиальных $\mathrm{SiC}$-приборов некоторых типов необходимо формировать мезаструктуры с наклонными стенками (см., например, [4,5]).

Мезаструктуры с пологими боковыми стенками могут использоваться для создания защитной фаски в высоковольтных 4H-SiC-приборах. В работе [6] нами проводилось численное моделирование пространственного распределения электрического поля в высоковольтных $(\sim 1500 \mathrm{~V})$ обратносмещенных мезаэпитаксиальных $4 H-\mathrm{SiC} p^{+}-p-n_{o}-n^{+}$-диодах с прямой фаской (модерируемую $p^{+}-p-n_{o}-n^{+}$-структуру имеют, в частности, дрейфовые диоды с резким восстановлением на основе $4 H-\mathrm{SiC}[7,8])$. Было показано, что снятие фаски под углами менее $10^{\circ}$ от плоскости $p-n_{o}$-перехода позволяет в несколько раз уменьшить краевое поверхностное поле по сравнению с полем в объеме (например, при угле фаски около $6^{\circ}$ краевое поле меньше объемного почти в 3 раза). 
$\mathrm{B}$ принципе прямая фаска в $\mathrm{SiC}$-приборах может быть создана с использованием фотолитографических методов и процессов селективного сухого травления. Для того чтобы стенки при травлении получались наклонными, необходимо обеспечить два условия: 1) маска и $\mathrm{SiC}$ должны травиться со сравнимыми скоростями; 2) край маски должен иметь форму острого клина. В качестве маски лучше всего подходит фоторезист, а наиболее подходящий способ травления — это традиционный для $\mathrm{SiC} \mathrm{RIE-процесс.}$

В настоящей работе с помощью фотолитографических методов и ионно-плазменных процессов изготовлены $\mathrm{SiC}$-мезаструктуры с пологими стенками, имеющими угол наклона около $8^{\circ}$.

\section{1. Геометрическая модель селективного травления}

На рис. 1 показана идеализированная геометрическая модель селективного сухого травления $\mathrm{SiC}$ с маской из фоторезиста. Наклонный профиль формируется при одновременном травлении $\mathrm{SiC}$ и резистивной маски, край которой имеет форму клина. Исходная поверхность $\mathrm{SiC}$ - плоская (сплошная линия 1 ), поверхность фоторезиста наклонена под углом $\alpha$ к поверхности $\mathrm{SiC}$ (сплошная линия 2). В процессе травления открытая поверхность $\mathrm{SiC}$ (на участке $A B$ ) травится на глубину $\Delta h_{\mathrm{SiC}}$. Фоторезист на участке $C D$ травится на глубину $\Delta h_{\mathrm{ph}}$. На участке ВС фоторезист стравливается за время процесса полностью, так, что после травления край фоторезиста сдвигается в латеральном направлении на расстояние $B C$ (пунктирная линия $2^{\prime}$ ). В результате поверхность $\mathrm{SiC}$ после травления на участке $B C$ оказывается наклоненной под углом $\beta$ к исходной поверхности пластины $\mathrm{SiC}$ (штриховая линия $\left(1^{\prime}\right)$. Легко убедиться, что

$$
\operatorname{tg}(\beta)=\operatorname{tg}(\alpha) /\left(\Delta h_{\mathrm{ph}} / \Delta h_{\mathrm{SiC}}\right) \equiv \operatorname{tg}(\alpha) / K,
$$

где $K$ - отношение скоростей травления фоторезиста и $\mathrm{SiC}$. Таким образом, из простых геометрических соображений следует, что результирующий угол

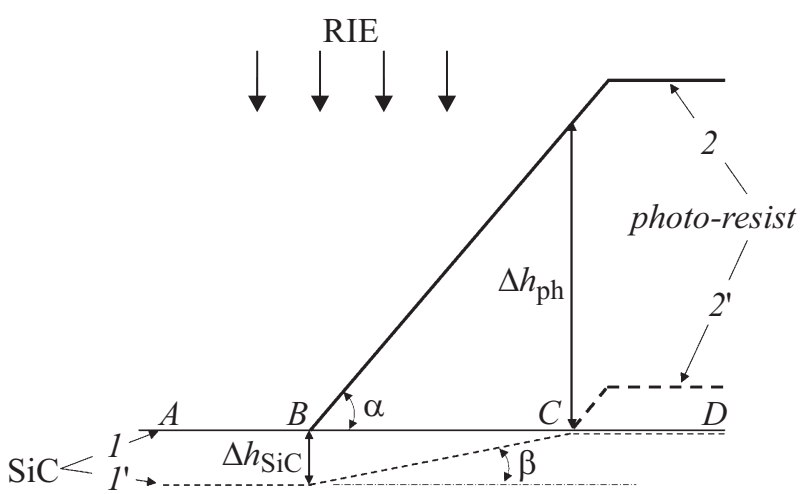

Рис. 1. Идеализированная модель селективного травления $\mathrm{SiC}$ с маской из фоторезиста.

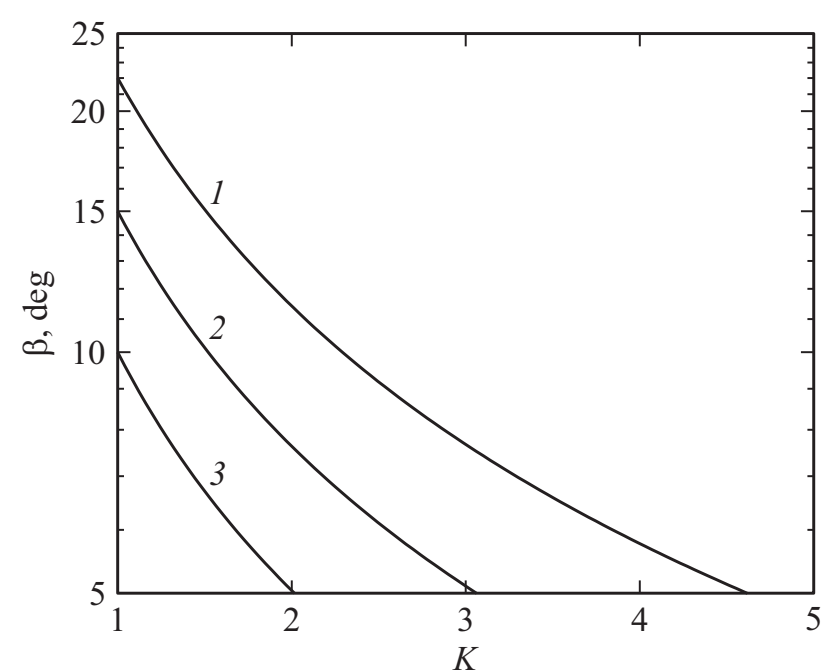

Рис. 2. Расчетные зависимости $\beta(K)$ при разных значениях $\alpha$ : $1-22^{\circ}, 2-15^{\circ}, 3-10^{\circ}$.

наклона стенки протравленной мезаструктуры $(\beta)$ должен задаваться двумя параметрами: исходным углом резистивного клина $(\alpha)$ и селективностью травления $\mathrm{SiC}$ по отношению к фоторезисту (величиной $K$ ). При селективности травления $1: 1(K=1)$ краевой профиль маски будет „копироваться“ в карбиде кремния. Важно то, что в случае технологических проблем по созданию фоторезистивной маски с малыми углами $\left(\alpha<10^{\circ}\right)$ эти проблемы могут быть решены подбором таких режимов травления, при которых скорость травления фоторезиста будет выше скорости травления $\mathrm{SiC}(K>1)$. Это проиллюстрировано на рис. 2, где показаны рассчитанные из соотношения (1) зависимости $\beta(K)$ при разных значениях $\alpha$. Например, при $\alpha=22^{\circ}$ результирующий угол $\beta=8^{\circ}$ получается при $K=2.9$ (селективность травления $\mathrm{SiC}$ по отношению к фоторезисту $1: 2.9$ ).

\section{2. Формирование SiC-мезаструктур}

Исходные пластины Si. Для изготовления SiC-мезаструктур использовались коммерческие $4 \mathrm{H}-\mathrm{SiC}$-подложки диаметром $76 \mathrm{~mm}$ с ориентацией (0001), с двухсторонней химико-механической полировкой, плотностью микропор менее $10 \mathrm{~cm}^{-2}$ (промышленное качество) и удельным сопротивлением около $0.02 \Omega \cdot \mathrm{cm}$ (n-тип проводимости). Из подложек вырезались фрагменты размером $20 \times 20 \mathrm{~mm}$. Микропрофилирование проводилось на $\mathrm{Si}$-стороне пластин. Перед нанесением фоторезиста обратная $C$-сторона пластин шлифовалась алмазной пастой с последующим напылением на шлифованную поверхность слоя никеля толщиной около $0.2 \mu \mathrm{m}$.

Формирование маски из фоторезиста. Использовались позитивные фоторезисты, состоящие из новолачной смолы, смешанной с небольшим количеством диазонафтохиноновой фотоактивной добавки. Эти фоторезисты 


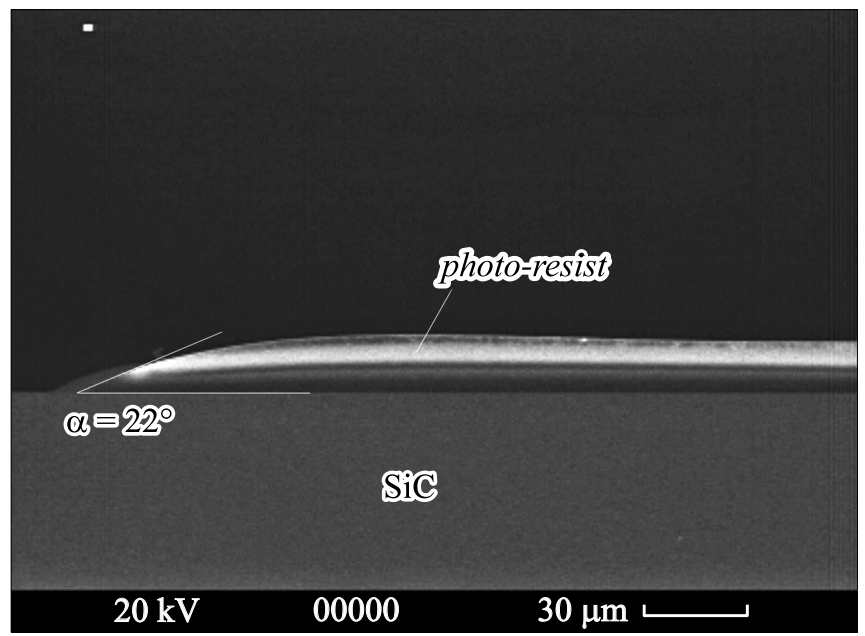

Рис. 3. Электронно-микроскопическое изображение профиля фоторезистивной маски. Толщина слоя фоторезиста $15 \mu \mathrm{m}$, угол краевого клина $22^{\circ}$.

обладают хорошей плазмостокостью и легко удаляются в органических растворителях. При термическом задубливании фоторезиста протекают сложные физикохимические процессы с участием смолы, чувствительного компонента, остаточного растворителя и воздуха [9]. Особенностью позитивных фоторезистов на основе новолачной смолы является их выраженное пластическое течение, которое наступает при температуре стеклования (ниже температуры задубливания) и зависит от конкретной марки фоторезиста. Задубливание приводит к оплавлению боковой стенки резиста; условия задубливания должны подбираться так, чтобы при заданном размере элемента достигались требуемые параметры: толщина слоя резиста и краевой угол. В экспериментах фоторезист AZ4562 наносился в два слоя методом центрифугирования (суммарная толщина пленки составляла $15-20 \mu \mathrm{m})$. Сушка проводилась в конвекционной печи при $90^{\circ} \mathrm{C}$ в течение $30 \mathrm{~min}$. Затем путем экспонирования и проявления в $1 \%$-м растворе $\mathrm{KOH}$ в слое резиста создавался рисунок - квадратные площадки разного размера. Задубливание проводилось в конвекционной печи при температуре $150^{\circ} \mathrm{C}$ в течение $60 \mathrm{~min}$. После изготовления элементов замерялись углы наклона их боковых стенок. Для этого снималось изображение сколов структур с помощью растрового электронного микроскопа CamScan S4-90FE. Оказалось, что угол наклона боковой стенки после задубливания зависит от толщины слоя резиста и от размеров элемента: на элементах размером от 100 до $600 \mu \mathrm{m}$ измеренные углы монотонно уменьшались от 42 до $22^{\circ}$ (при размерах элементов более $600 \mu \mathrm{m}$ угол уже не изменялся). Для последующего травления мезаструктур использовались образцы с маскирующими площадками, имеющими угол наклона боковых стенок $22^{\circ}$ (рис. 3 ).

Реактивно-ионное травление $\mathrm{SiC}$ с резистивной маской. Решаемая в наситоящей работе задача фор- мирования мезаструктур с пологими стенками ориентирована на изготовление в будущем высоковольтных $4 H-\mathrm{SiC} p^{+}-p-n_{o}-n^{+}$-диодов с прямой фаской. В работе [6] с помощью моделирования было показано, что для $1500-\mathrm{V}$ диода эффективной должна быть прямая фаска с углом менее $10^{\circ}$ относительно плоскости $p-n_{o}$-перехода; при этом глубина травления $\mathrm{SiC}$ должна немного превышать суммарную толщину всех слоев $p$-типа (около $3 \mu \mathrm{m}$ ). Исходя из этого, а также из результатов, показанных на рис. 2 и 3, к травлению предъявлялись следующие требования:

- глубина травления $\mathrm{SiC}$ должна составлять не менее $3 \mu \mathrm{m}$ (при этом скорость травления должна обеспечивать приемлемое морфологическое совершенство протравленной поверхности $\mathrm{SiC}$ );

- коэффициент $K$ должен варьироваться в зависимости от заданного значения угла $\beta$ : при углах $\beta$ в пределах $6-10^{\circ}$ коэффициент $K$ необходимо изменять в пределах от 2.3 до 3.8 (рис. 2);
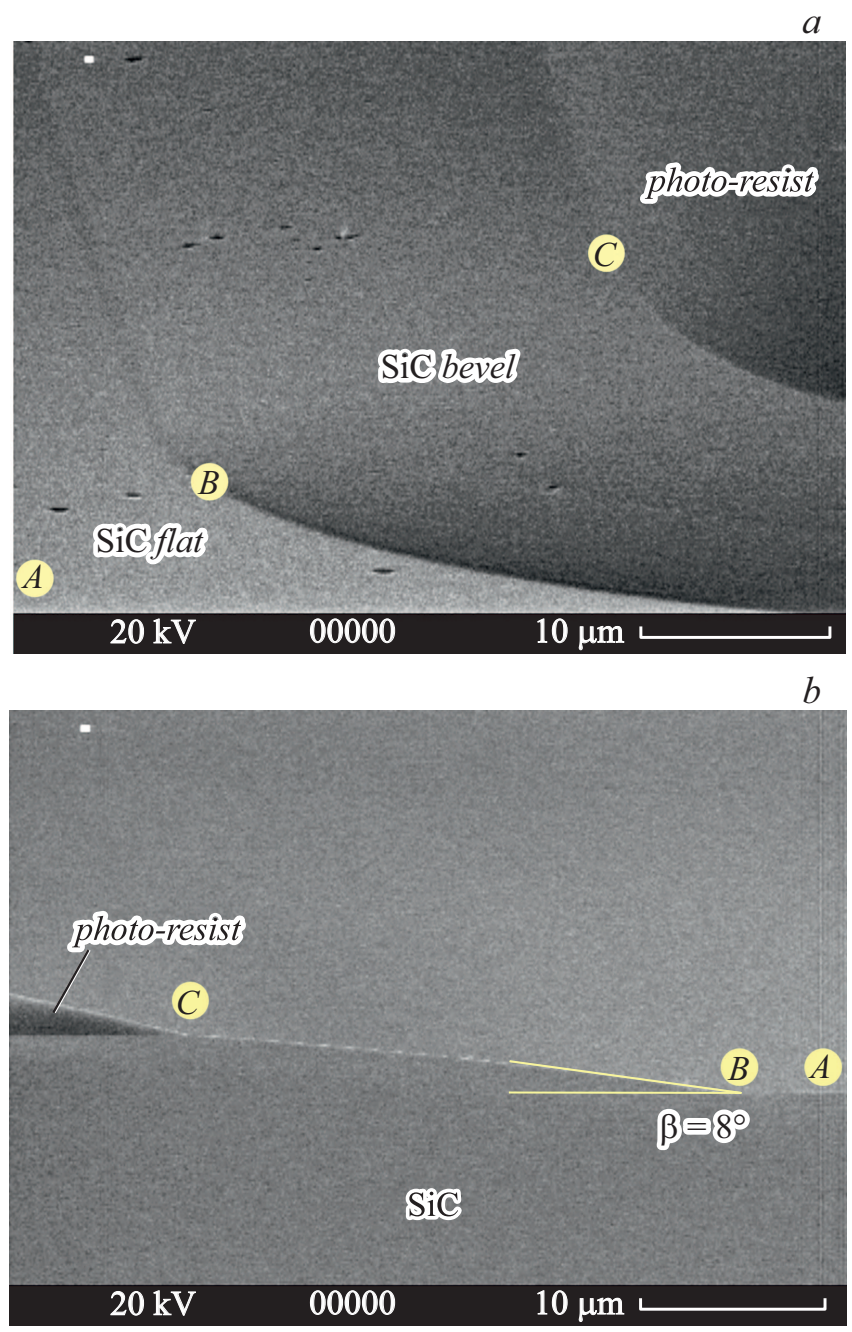

Рис. 4. Электронно-микроскопическое изображение протравленной $\mathrm{SiC}$ мезаструктуры: $a-$ поверхность, $b-$ скол. Участок $A B$ - плоское дно, участок $B C-$ пологая боковая стенка с углом наклона $8^{\circ}$. 
Параметры селективного травления $\mathrm{SiC}$ с маской из фоторезиста

\begin{tabular}{l|c}
\hline Глубина травления $\mathrm{SiC}, \mu \mathrm{m}$ & 3.2 \\
\hline Скорость травления $\mathrm{SiC}, \mathrm{nm} / \mathrm{min}$ & 53 \\
\hline Скорость травления фоторезиста, $\mathrm{nm} / \mathrm{min}$ & 160 \\
\hline $\begin{array}{l}\text { Селективность травления } \mathrm{SiC} \text { по отношению } \\
\text { к фоторезисту }\end{array}$ & $1: 3$ \\
\hline $\begin{array}{l}\text { Результирующий угол наклона стенки } \\
\text { мезаструктуры }(\beta),{ }^{\circ}\end{array}$ & 8
\end{tabular}

- толщина слоя фоторезиста должна составлять не менее $12 \mu \mathrm{m}$; это необходимо, например, в случае травления $\mathrm{SiC}$ на глубину $3 \mu \mathrm{m}$ с селективностью травления по отношению к фоторезисту $1: 3.8$.

Эксперименты по травлению проводились в лабораторном ICP-реакторе, в ВЧ-плазме $\mathrm{NF}_{3}$. Экспериментально подбирались оптимальные параметры процесса: селективность и скорость травления. С этой целью варьировались мощность ВЧ-разряда и давление рабочего газа в реакционной камере. И мощность, и давление по возможности выбирались малыми (при условии сохранения приемлемой скорости травления) для того, чтобы обеспечить высокое морфологическое качество протравленных поверхностей $\mathrm{SiC}$. Наилучшие результаты, с точки зрения достижения требуемых параметров глубины травления $\mathrm{SiC}$ и угла наклона боковых стенок мезаструктур - были получены при мощности ВЧразряда в пределах $20-50 \mathrm{~W}$ и давлении газа $0.4 \mathrm{~Pa}$. На рис. 4 показаны микрорельефы, полученные при травлении $\mathrm{SiC}$ в данном режиме, а в таблице сведены достигнутые значения параметров травления. Отметим, что полученный экспериментально результат $\left(\beta=8^{\circ}\right.$ при $K=3$ ) совпадает с результатом, который предсказывает рассмотренная выше простая модель (рис. 2). Как видно из рис. 4 , и дно, и образующиеся стенки мезаструктуры довольно гладкие. При этом на поверхности $\mathrm{SiC}$ можно видеть отдельные ямки травления, образование которых обусловлено, по-видимому, наличием в объеме $\mathrm{SiC}$ проникающих дислокаций (плотность дислокаций в использованных коммерческих $4 \mathrm{H}-\mathrm{SiC}$ подложках составляет до $\left.10^{3} \mathrm{~cm}^{-2}\right)$.

\section{Заключение}

В работе продемонстрировано формирование $\mathrm{SiC}-\mathrm{Me}-$ заструктур (высотой $3 \mu \mathrm{m}$ ) с пологими боковыми стенками (угол наклона $8^{\circ}$ ) с помощью процесса RIE через маску из фоторезиста. Данная технология может использоваться при изготовлении высоковольтных $\mathrm{SiC}$-приборов с прямой фаской.

Из полученных модельных и экспериментальных результатов следует, что критически важными параметрами, определяющими конечную геометрию формируемых мезаструктур, являются исходный краевой угол маски и селективность травления $\mathrm{SiC}$ по отношению к маске. Как показала практика, на фоторезистивных маскирующих элементах добиться углов менее $20^{\circ}$ чрезвычайно сложно, если вообще возможно. Однако технологические проблемы по созданию фоторезистивной маски с малыми углами могут быть решены коррекцией селективности травления. Для варьирования селективности травления могут быть предложены разные подходы. В частности, для увеличения скорости травления фоторезиста (при сохранении скорости травления $\mathrm{SiC}$ ) может быть опробовано реактивно-ионное травление $\mathrm{SiC}$ в смеси фторсодержащего газа с кислородом (в полупроводниковой технологии удаление фоторезиста в кислородной плазме является стандартной технологией). Кроме того, для варьирования селективности перспективными могут быть другие известные методы сухого травления, такие как ионно-лучевое травление под углом $45^{\circ}$ к поверхности $\mathrm{SiC}$ и реактивное ионнолучевое травление.

\section{Конфликт интересов}

Авторы заявляют, что у них нет конфликта интересов.

\section{Список литературы}

[1] Сыркин А.Л., Попов И.В., Челноков В.Е. // Письма в ЖТФ. 1986. Т. 12. Вып. 4. С. 240-243.

[2] Palmour J.W., Davis R.F., Wallett T.M., Bhasin K.B. // J. Vacuum Sci. Technol. A4. 1986. Vol. 4. N 3. P. 590-593. DOI.org/10.1116/1.573854

[3] Pan W.S., Steckl A.J. In: SPP Amorphous and Crystalline Silicon Carbide / Ed. by M.M. Rahman, C.Y.-W. Yang, G.L. Harris. Springer Verlag. Berlin, Heidelberg, 1989. P. 217.

[4] Yano H., Hirao T., Kimoto T., Matsunami H., Shiomi H. // Appl. Phys. Lett. 2002. Vol. 81. N 25. P. 4772-4774. DOI.org/10.1063/1.1529313

[5] Ильинская Н.Д., Лебедева Н.М., Задиранов Ю.М., Иванов П.А., Самсонова Т.П., Коньков О.И., Потапов А.С. // ФТП. 2020. Т. 54. Вып. 1. С. 97-102. DOI: $10.21883 /$ FTP.2020.01.48783.9223

[6] Лебедева Н.М., Ильинская Н.Д., Иванов П.А. // ФТП. 2020. Т. 54. Вып. 2. С. 207-211.

[7] Иванов П.А., Грехов И.В. // ЖТФ. 2015. Т. 85. Вып. 6. C. $111-117$.

[8] Иванов П.А., Коньков О.И., Самсонова Т.П., Потапов А.С. // Письма в ЖТФ. 2018. Т. 44. Вып. 3. С. 3-8. DOI: 10.21883/PJTF.2018.03.45572.17025

[9] Моро У. Микролитография: Принципы, методы, материалы. М: Мир, 1990. 1237 с. 